\title{
Approximately Quintic and Sextic Mappings Form $r$-Divisible Groups into Ŝerstnev Probabilistic Banach Spaces: Fixed Point Method
}

\author{
M. Eshaghi Gordji, ${ }^{1,2}$ Y. J. Cho, ${ }^{3}$ M. B. Ghaemi, ${ }^{4}$ and H. Majani ${ }^{4}$ \\ ${ }^{1}$ Department of Mathematics, Semnan University, P.O. Box 35195-363, Semnan, Iran \\ ${ }^{2}$ Center of Excellence in Nonlinear Analysis and Applications (CENAA), Semnan University, \\ Semnan, Iran \\ ${ }^{3}$ Department of Mathematics Education and the RINS, Gyeongsang National University, \\ Chinju 660-701, Republic of Korea \\ ${ }^{4}$ Department of Mathematics, Iran University of Science \& Technology, Narmak, Tehran 16844, Iran
}

Correspondence should be addressed to Y. J. Cho, yjcho@gnu.ac.kr

Received 1 September 2011; Accepted 12 October 2011

Academic Editor: Carlo Piccardi

Copyright (C) 2011 M. Eshaghi Gordji et al. This is an open access article distributed under the Creative Commons Attribution License, which permits unrestricted use, distribution, and reproduction in any medium, provided the original work is properly cited.

Using the fixed point method, we investigate the stability of the systems of quadratic-cubic and additive-quadratic-cubic functional equations with constant coefficients form $r$-divisible groups into Serstnev probabilistic Banach spaces.

\section{Introduction and Preliminaries}

The stability problem of functional equations started with the following question concerning stability of group homomorphisms proposed by Ulam [1] during a talk before a Mathematical Colloquium at the University of Wisconsin, Madison, in 1940.

Let $\left(G_{1}, \cdot\right)$ be a group and $\left(G_{2}, *\right)$ a metric group with the metric $d(\cdot, \cdot)$. Given $\epsilon>0$, does there exist a $\delta>0$ such that if a mapping $h: G_{1} \rightarrow G_{2}$ satisfies the inequality $d(h(x \cdot y)$, $h(x) * h(y))<\delta$ for all $x, y \in G_{1}$, then there exists a homomorphism $H: G_{1} \rightarrow G_{2}$ with $d(h(x), H(x))<\epsilon$ for all $x \in G_{1}$ ?

In 1941, Hyers [2] gave a first affirmative answer to the question of Ulam for Banach spaces as follows.

If $E$ and $E^{\prime}$ are Banach spaces and $f: E \rightarrow E^{\prime}$ is a mapping for which there is $\varepsilon>0$ such that $\|f(x+y)-f(x)-f(y)\| \leq \varepsilon$ for all $x, y \in E$, then there is a unique additive mapping $L: E \rightarrow E^{\prime}$ such that $\|f(x)-L(x)\| \leq \varepsilon$ for all $x \in E$. 
Hyers' Theorem was generalized by Aoki [3] for additive mappings and by Rassias [4] for linear mappings by considering an unbounded Cauchy difference, respectively.

The paper of Rassias [5] has provided a lot of influence in the development of what we now call the generalized Hyers-Ulam stability or as Hyers-Ulam-Rassias stability of functional equations. In 1994, a generalization of the Rassias theorem was obtained by Găvruţa [6] by replacing the unbounded Cauchy difference by a general control function in the spirit of Rassias' approach. For more details about the results concerning such problems, the reader is referred to $[4,5,7-21,21-30]$.

The functional equation

$$
f(x+y)+f(x-y)=2 f(x)+2 f(y)
$$

is related to a symmetric biadditive function [31,32]. It is natural that this equation is called a quadratic functional equation. In particular, every solution of the quadratic equation (1.1) is called a quadratic function. The Hyers-Ulam stability problem for the quadratic functional equation was solved by Skof [33]. In [8], Czerwik proved the Hyers-Ulam-Rassias stability of (1.1). Eshaghi Gordji and Khodaei [34] obtained the general solution and the generalized Hyers-Ulam-Rassias stability of the following quadratic functional equation: for all $a, b \in$ $\mathbb{Z} \backslash\{0\}$ with $a \neq \pm 1, \pm b$,

$$
f(a x+b y)+f(a x-b y)=2 a^{2} f(x)+2 b^{2} f(y) .
$$

Jun and Kim [35] introduced the following cubic functional equation:

$$
f(2 x+y)+f(2 x-y)=2 f(x+y)+2 f(x-y)+12 f(x)
$$

and they established the general solution and the generalized Hyers-Ulam-Rassias stability for the functional equation (1.3). Jun et al. [36] investigated the solution and the Hyers-Ulam stability for the cubic functional equation

$$
f(a x+b y)+f(a x-b y)=a b^{2}(f(x+y)+f(x-y))+2 a\left(a^{2}-b^{2}\right) f(x),
$$

where $a, b \in \mathbb{Z} \backslash\{0\}$ with $a \neq \pm 1, \pm b$. For other cubic functional equations, see [37].

Lee et al. [38] considered the following functional equation:

$$
f(2 x+y)+f(2 x-y)=4 f(x+y)+4 f(x-y)+24 f(x)-6 f(y) .
$$

In fact, they proved that a function $f$ between two real vector spaces $X$ and $Y$ is a solution of (1.5) if and only if there exists a unique symmetric biquadratic function $B_{2}: X \times$ $X \rightarrow Y$ such that $f(x)=B_{2}(x, x)$ for all $x \in X$. The bi-quadratic function $B_{2}$ is given by

$$
B_{2}(x, y)=\frac{1}{12}(f(x+y)+f(x-y)-2 f(x)-2 f(y))
$$


Obviously, the function $f(x)=c x^{4}$ satisfies the functional equation (1.5), which is called the quartic functional equation. For other quartic functional equations, see [39].

Ebadian et al. [40] considered the generalized Hyers-Ulam stability of the following systems of the additive-quartic functional equations:

$$
\begin{aligned}
f\left(x_{1}+x_{2}, y\right)=f\left(x_{1}, y\right)+f\left(x_{2}, y\right) & \\
f\left(x, 2 y_{1}+y_{2}\right)+f\left(x, 2 y_{1}-y_{2}\right)= & 4 f\left(x, y_{1}+y_{2}\right)+4 f\left(x, y_{1}-y_{2}\right) \\
& +24 f\left(x, y_{1}\right)-6 f\left(x, y_{2}\right)
\end{aligned}
$$

and the quadratic-cubic functional equations:

$$
\begin{aligned}
& f\left(x, 2 y_{1}+y_{2}\right)+f\left(x, 2 y_{1}-y_{2}\right) \\
& \quad=2 f\left(x, y_{1}+y_{2}\right)+2 f\left(x, y_{1}-y_{2}\right)+12 f\left(x, y_{1}\right) \\
& f\left(x, y_{1}+y_{2}\right)+f\left(x, y_{1}-y_{2}\right)=2 f\left(x, y_{1}\right)+2 f\left(x, y_{2}\right) .
\end{aligned}
$$

For more details about the results concerning mixed type functional equations, the readers are referred to [41-44].

Recently, Ghaemi et al. [45] investigated the stability of the following systems of quadratic-cubic functional equations:

$$
\begin{aligned}
& f\left(a x_{1}+b x_{2}, y\right)+f\left(a x_{1}-b x_{2}, y\right)=2 a^{2} f\left(x_{1}, y\right)+2 b^{2} f\left(x_{2}, y\right), \\
& f\left(x, a y_{1}+b y_{2}\right)+f\left(x, a y_{1}-b y_{2}\right) \\
& \quad=a b^{2}\left(f\left(x, y_{1}+y_{2}\right)+f\left(x, y_{1}-y_{2}\right)\right)+2 a\left(a^{2}-b^{2}\right) f\left(x, y_{1}\right),
\end{aligned}
$$

and additive-quadratic-cubic functional equations:

$$
\begin{aligned}
f\left(a x_{1}+b x_{2}, y, z\right)+f\left(a x_{1}-b x_{2}, y, z\right)= & 2 a f\left(x_{1}, y, z\right) \\
f\left(x, a y_{1}+b y_{2}, z\right)+f\left(x, a y_{1}-b y_{2}, z\right)= & 2 a^{2} f\left(x, y_{1}, z\right)+2 b^{2} f\left(x, y_{2}, z\right) \\
f\left(x, y, a z_{1}+b z_{2}\right)+f\left(x, y, a z_{1}-b z_{2}\right)= & a b^{2}\left(f\left(x, y, z_{1}+z_{2}\right)+f\left(x, y, z_{1}-z_{2}\right)\right) \\
+ & +2 a\left(a^{2}-b^{2}\right) f\left(x, y, z_{1}\right)
\end{aligned}
$$

in PN-spaces (see Definition 1.6), where $a, b \in \mathbb{Z} \backslash\{0\}$ with $a \neq \pm 1, \pm b$. The function $f$ : $\mathbb{R} \times \mathbb{R} \rightarrow \mathbb{R}$ given by $f(x, y)=c x^{2} y^{3}$ is a solution of the system (1.9). In particular, letting $y=x$, we get a quintic function $g: \mathbb{R} \rightarrow \mathbb{R}$ in one variable given by $g(x):=f(x, x)=c x^{5}$. Also, it is easy to see that the function $f: \mathbb{R} \times \mathbb{R} \times \mathbb{R} \rightarrow \mathbb{R}$ defined by $f(x, y, z)=c x y^{2} z^{3}$ is a solution of the system (1.10). In particular, letting $y=z=x$, we get a sextic function $h: \mathbb{R} \rightarrow \mathbb{R}$ in one variable given by $h(x):=f(x, x, x)=c x^{6}$.

The proof of the following propositions are evident. 
Proposition 1.1. Let $X$ and $Y$ be real linear spaces. If a function $f: X \times X \rightarrow Y$ satisfies the system (1.9), then $f(\lambda x, \mu y)=\lambda^{2} \mu^{3} f(x, y)$ for all $x, y \in X$ and rational numbers $\lambda, \mu$.

Proposition 1.2. Let $X$ and $Y$ be real linear spaces. If a function $f: X \times X \times X \rightarrow Y$ satisfies the system (1.10), then $f(\lambda x, \mu y, \eta z)=\lambda \mu^{2} \eta^{3} f(x, y, z)$ for all $x, y, z \in X$ and rational numbers $\lambda, \mu, \eta$.

For our main results, we introduce Banach's fixed point theorem and related results. For the proof of Theorem 1.3, refer to [46] and also Chapter 5 in [29] and, for more fixed point theory and other nonlinear methods, refer to [28, 47]. Especially, in 2003, Radu [27] proposed a new method for obtaining the existence of exact solutions and error estimations, based on the fixed point alternative (see also [48-53]).

Let $(X, d)$ be a generalized metric space. We say that an operator $T: X \rightarrow X$ satisfies a Lipschitz condition with Lipschitz constant $L$ if there exists a constant $L \geq 0$ such that $d(T x, T y) \leq L d(x, y)$ for all $x, y \in X$. If the Lipschitz constant $L$ is less than 1, then the operator $T$ is called a strictly contractive operator.

Note that the distinction between the generalized metric and the usual metric is that the range of the former is permitted to include the infinity. We recall the following theorem by Margolis and Diaz.

Theorem 1.3 (see $[27,46])$. Suppose that $(\Omega, d)$ is a complete generalized metric space and $T: \Omega \rightarrow$ $\Omega$ is a strictly contractive mapping with Lipschitz constant L. Then, for any $x \in \Omega$, either

$$
d\left(T^{m} x, T^{m+1} x\right)=\infty
$$

for all $m \geq 0$ or there exists a natural number $m_{0}$ such that

(1) $d\left(T^{m} x, T^{m+1} x\right)<\infty$ for all $m \geq m_{0}$;

(2) the sequence $\left\{T^{m} x\right\}$ is convergent to a fixed point $y^{*}$ of $T$;

(3) $y^{*}$ is the unique fixed point of $T$ in $\Lambda=\left\{y \in \Omega: d\left(T^{m_{0}} x, y\right)<\infty\right\}$;

(4) $d\left(y, y^{*}\right) \leq(1 / 1-L) d(y, T y)$ for all $y \in \Lambda$.

The PN-spaces were first defined by Šerstnev in 1963 (see [54]). Their definition was generalized by Alsina et al. in [55]. In this paper, we follow the definition of probabilistic space briefly as given in [56] (also, see [57]).

Definition 1.4. A distance distribution function (d.d.f.) is a nondecreasing function $F$ from $\overline{\mathbb{R}}^{+}$ into $[0,1]$ that satisfies $F(0)=0, F(+\infty)=1$ and $F$ is left-continuous on $(0,+\infty)$, where $\overline{\mathbb{R}}^{+}:=[0,+\infty]$.

Forward, the space of distance distribution functions is denoted by $\Delta^{+}$and the set of all $F$ in $\Delta^{+}$with $\lim _{t \rightarrow+\infty} F(t)=1$ by $D^{+}$. The space $\Delta^{+}$is partially ordered by the usual pointwise ordering of functions, that is, $F \leq G$ if and only if $F(x) \leq G(x)$ for all $x$ in $\overline{\mathbb{R}}^{+}$. For any $a \geq 0, \varepsilon_{a}^{+}$ is the d.d.f. given by

$$
\varepsilon_{a}^{+}(t)= \begin{cases}0, & \text { if } t \leq a \\ 1, & \text { if } t>a\end{cases}
$$


Definition 1.5. A triangle function is a binary operation on $\Delta^{+}$, that is, a function $\tau: \Delta^{+} \times \Delta^{+} \rightarrow$ $\Delta^{+}$that is associative, commutative, non-decreasing in each place, and has $\varepsilon_{0}$ as the identity, that is, for all $F, G$ and $H$ in $\Delta^{+}$,

$$
\begin{aligned}
& \text { (TF1) } \tau(\tau(F, G), H)=\tau(F, \tau(G, H)) ; \\
& \text { (TF2) } \tau(F, G)=\tau(G, F) ; \\
& \text { (TF3) } F \leq G \Rightarrow \tau(F, H) \leq \tau(G, H) ; \\
& \text { (TF4) } \tau\left(F, \varepsilon_{0}\right)=\tau\left(\varepsilon_{0}, F\right)=F .
\end{aligned}
$$

Typical continuous triangle function is

$$
\Pi_{T}(F, G)(x)=T(F(x), G(x))
$$

where $T$ is a continuous $t$-norm, that is, a continuous binary operation on $[0,1]$ that is commutative, associative, non-decreasing in each variable, and has 1 as the identity. For example, we introduce the following:

$$
M(x, y)=\min (x, y)
$$

for all $x, y \in[0,1]$ is a continuous and maximal $t$-norm, namely, for any $t$-norm $T, M \geq T$. Also, note that $\Pi_{M}$ is a maximal triangle function, that is, for all triangle function $\tau, \Pi_{M} \geq \tau$.

Definition 1.6. A Šerstnev probabilistic normed space (Šerstnev PN-space) is a triple $(X, v, \tau)$, where $X$ is a real vector space, $\tau$ is continuous triangle function, and $v$ is a mapping (the probabilistic norm) from $X$ into $\Delta^{+}$such that, for all choice of $p, q \in X$ and $a \in \mathbb{R}^{+}$, the following conditions hold:

(N1) $v(p)=\varepsilon_{0}$, if and only if $p=\theta(\theta$ is the null vector in $X)$;

$(\mathrm{N} 2) \mathcal{v}(a p)(t)=v(p)(t /|a|)$;

(N3) $v(p+q) \geq \tau(v(p), v(q))$.

Let $(X, v, \tau)$ be a PN-space and $\left\{x_{n}\right\}$ a sequence in $X$. Then $\left\{x_{n}\right\}$ is said to be convergent if there exists $x \in X$ such that

$$
\lim _{n \rightarrow \infty} \mathcal{v}\left(x_{n}-x\right)(t)=1
$$

for all $t>0$. In this case, the point $x$ is called the limit of $\left\{x_{n}\right\}$. The sequence $\left\{x_{n}\right\}$ in $(X, v, \tau)$ is called a Cauchy sequence if, for any $\varepsilon>0$ and $\delta>0$, there exists a positive integer $n_{0}$ such that $v\left(x_{n}-x_{m}\right)(\delta)>1-\varepsilon$ for all $m, n \geq n_{0}$. Clearly, every convergent sequence in a PN-space is a Cauchy sequence. If each Cauchy sequence is convergent in a PN-space $(X, v, \tau)$, then $(X, v, \tau)$ is called a probabilistic Banach space (PB-space).

For more details about the results concerning stability of the functional equations on $\mathrm{PN}$-spaces, the readers are referred to [58-61].

In this paper, by using the fixed point method, we establish the stability of the systems (1.9) and (1.10) form $r$-divisible groups into Šerstnev PB-space. 


\section{Mail Results}

We start our work by the following theorem which investigates the stability problem for the system of the functional equations (1.9) form $r$-divisible groups into Šerstnev PB-space by using fixed point methods.

Theorem 2.1. Let $s \in\{-1,1\}$ be fixed. Let $G$ be an $r$-divisible group and $\left(Y, v, \Pi_{T}\right)$ a Šerstnev $P B$-space. Let $\phi, \psi: G \times G \times G \rightarrow D^{+}$be two functions such that

$\Phi(x, y)(t):=\Pi_{T}\left\{\phi\left(a^{(s-1) / 2} x, 0, a^{(s-1) / 2} y\right)\left(2 a^{(5 s-1) / 2} t\right), \psi\left(a^{(s+1) / 2} x, a^{(s-1) / 2} y, 0\right)\left(2 a^{(5 s+5) / 2} t\right)\right\}$

for all $x, y \in G$ and, for some $0<k<a^{10 s,}$

$$
\begin{gathered}
\Phi\left(a^{s} x, a^{s} y\right)\left(k a^{-2 s} t\right) \geq \Phi(x, y)(t) \\
\lim _{n \rightarrow \infty} \phi\left(a^{s n} x_{1}, a^{s n} x_{2}, a^{s n} y\right)\left(a^{-5 s n} t\right)=\lim _{n \rightarrow \infty} \psi\left(a^{s n} x, a^{s n} y_{1}, a^{s n} y_{2}\right)\left(a^{-5 s n} t\right)=1
\end{gathered}
$$

for all $x, y, x_{1}, x_{2}, y_{1}, y_{2} \in G$ and $t>0$. If $f: G \times G \rightarrow Y$ is a function such that $f(0, y)=0$ for all $y \in G$ and

$$
\begin{aligned}
& v\left(f\left(a x_{1}+b x_{2}, y\right)+f\left(a x_{1}-b x_{2}, y\right)-2 a^{2} f\left(x_{1}, y\right)-2 b^{2} f\left(x_{2}, y\right)\right)(t) \geq \phi\left(x_{1}, x_{2}, y\right), \\
& v\left(f\left(x, a y_{1}+b y_{2}\right)+f\left(x, a y_{1}-b y_{2}\right)-a b^{2} f\left(x, y_{1}+y_{2}\right)\right. \\
& \left.\quad-a b^{2} f\left(x, y_{1}-y_{2}\right)-2 a\left(a^{2}-b^{2}\right) f\left(x, y_{1}\right)\right)(t) \geq \psi\left(x, y_{1}, y_{2}\right)
\end{aligned}
$$

for all $x, y, x_{1}, x_{2}, y_{1}, y_{2} \in G$, then there exists a unique quintic function $T: G \times G \rightarrow Y$ satisfying the system (1.9) and

$$
v(f(x, y)-T(x, y))(t) \geq \Phi(x, y)\left(\left(1-k a^{-10 s}\right) t\right)
$$

for all $x, y \in G$.

Proof. Putting $x_{1}=2 x$ and $x_{2}=0$ and replacing $y$ by $2 y$ in (2.3), we get

$$
v\left(f(2 a x, 2 y)-a^{2} f(2 x, 2 y)\right)(t) \geq \phi(2 x, 0,2 y)(2 t)
$$

for all $x, y \in G$. Putting $y_{1}=2 y$ and $y_{2}=0$ and replacing $x$ by $2 a x$ in (2.4), we get

$$
v\left(f(2 a x, 2 a y)-a^{3} f(2 a x, 2 y)\right)(t) \geq \psi(2 a x, 2 y, 0)(2 t)
$$


for all $x, y \in G$. Thus, we have

$$
v\left(f(2 a x, 2 a y)-a^{5} f(2 x, 2 y)\right)(t) \geq \Pi_{T}\left\{\phi(2 x, 0,2 y)\left(2 a^{-3} t\right), \psi(2 a x, 2 y, 0)(2 t)\right\}
$$

for all $x, y \in G$. Replacing $x, y$ by $x / 2, y / 2$ in (2.8), we have

$$
v\left(f(a x, a y)-a^{5} f(x, y)\right)(t) \geq \Pi_{T}\left\{\phi(x, 0, y)\left(2 a^{-3} t\right), \psi(a x, y, 0)(2 t)\right\}
$$

for all $x, y \in G$. It follows from (2.9) that

$$
\begin{gathered}
v\left(a^{-5} f(a x, a y)-f(x, y)\right)(t) \geq \Pi_{T}\left\{\phi(x, 0, y)\left(2 a^{2} t\right), \psi(a x, y, 0)\left(2 a^{5} t\right)\right\}, \\
v\left(a^{5} f\left(a^{-1} x, a^{-1} y\right)-f(x, y)\right)(t) \geq \Pi_{T}\left\{\phi\left(a^{-1} x, 0, a^{-1} y\right)\left(2 a^{-3} t\right), \psi\left(a x, a^{-1} y, 0\right)(2 t)\right\}
\end{gathered}
$$

for all $x, y \in G$. So we have

$$
v\left(a^{-5 s} f\left(a^{s} x, a^{s} y\right)-f(x, y)\right)(t) \geq \Phi(x, y)(t)
$$

for all $x, y \in G$. Let $S$ be the set of all mappings $h: G \times G \rightarrow Y$ with $h(0, x)=0$ for all $x \in G$, and define a generalized metric on $S$ as follows:

$$
d(h, k)=\inf \left\{u \in \mathbb{R}^{+}: v(h(x, y)-k(x, y))(u t) \geq \Phi(x, y)(t), \forall x, y \in G, \forall t>0\right\},
$$

where, as usual, $\inf \emptyset=+\infty$. The proof of the fact that $(S, d)$ is a complete generalized metric space, can be shown in $[48,62]$.

Now, we consider the mapping $J: S \rightarrow S$ defined by

$$
J h(x, y):=a^{-5 s} h\left(a^{s} x, a^{s} y\right)
$$

for all $h \in S$ and $x, y \in G$. Let $f, g \in S$ such that $d(f, g)<\varepsilon$. Then it follows that

$$
\begin{aligned}
v(J g & (x, y)-J f(x, y))\left(k u a^{-10 s} t\right) \\
& =v\left(a^{-5 s} g\left(a^{s} x, a^{s} y\right)-a^{-5 s} f\left(a^{s} x, a^{s} y\right)\right)\left(k u a^{-10 s} t\right) \\
& =v\left(g\left(a^{s} x, a^{s} y\right)-f\left(a^{s} x, a^{s} y\right)\right)\left(k u a^{-2 s} t\right) \\
& \geq \Phi\left(a^{s} x, a^{s} y\right)\left(k a^{-2 s} t\right) \\
& \geq \Phi(x, y)(t),
\end{aligned}
$$


that is, if $d(f, g)<\varepsilon$, then we have $d(J f, J g)<k a^{-10 s} \varepsilon$. This means that

$$
d(J f, J g) \leq k a^{-10 s} d(f, g)
$$

for all $f, g \in S$; that is, $J$ is a strictly contractive self-mapping on $S$ with the Lipschitz constant $k a^{-10 s}$. It follows from (2.11) that

$$
v(J f(x, y)-f(x, y))(t) \geq \Phi(x, y)(t)
$$

for all $x, y \in G$ and $t>0$, which implies that $d(J f, f) \leq 1$. From Theorem 1.3, it follows that there exists a unique mapping $T: G \times G \rightarrow Y$ such that $T$ is a fixed point of $J$, that is, $T\left(a^{s} x, a^{s} y\right)=a^{5 s} T(x, y)$ for all $x, y \in G$. Also, we have $d\left(J^{m} g, T\right) \rightarrow 0$ as $m \rightarrow \infty$, which implies the equality

$$
\lim _{m \rightarrow \infty} a^{-5 s m} f\left(a^{s m} x, a^{s m} y\right)=T(x)
$$

for all $x, y \in G$. It follows from (2.3) that

$$
\begin{aligned}
v(T( & \left.\left.a x_{1}+b x_{2}, y\right)+T\left(a x_{1}-b x_{2}, y\right)-2 a^{2} T\left(x_{1}, y\right)-2 b^{2} \mathrm{~T}\left(x_{2}, y\right)\right)(t) \\
= & \lim _{n \rightarrow \infty} v\left(a^{-5 s n} f\left(a^{s n}\left(a x_{1}+b x_{2}\right), a^{s n} y\right)+a^{-5 s n} f\left(a^{s n}\left(a x_{1}-b x_{2}\right), a^{s n} y\right)\right. \\
& \left.-2 a^{-5 s n} a^{2} f\left(a^{s n} x_{1}, a^{s n} y\right)-2 a^{-5 s n} b^{2} f\left(a^{s n} x_{2}, a^{s n} y\right)\right)(t) \\
\geq & \lim _{n \rightarrow \infty} \phi\left(a^{s n} x_{1}, a^{s n} x_{2}, a^{s n} y\right)\left(a^{-5 s n} t\right) \\
= & 1
\end{aligned}
$$

for all $x_{1}, x_{2}, y \in \mathrm{G}$. Also, it follows from (2.4) that

$$
\begin{gathered}
v\left(T\left(x, a y_{1}+b y_{2}\right)+T\left(x, a y_{1}-b y_{2}\right)\right. \\
\left.-a b^{2}\left(T\left(x, y_{1}+y_{2}\right)-T\left(x, y_{1}-y_{2}\right)\right)-2 a\left(a^{2}-b^{2}\right) T\left(x, y_{1}\right)\right)(t) \\
=\lim _{n \rightarrow \infty} v\left(a^{-5 s n} f\left(a^{s n} x, a^{s n}\left(a y_{1}+b y_{2}\right)\right)+a^{-5 s n} f\left(a^{s n} x, a^{s n}\left(a y_{1}-b y_{2}\right)\right)\right. \\
\quad-a^{-5 s n} a b^{2} f\left(a^{s n} x, a^{s n}\left(y_{1}+y_{2}\right)\right)-a^{-5 s n} a b^{2} f\left(a^{s n} x, a^{s n}\left(y_{1}-y_{2}\right)\right) \\
\left.\quad-2 a^{-5 s n} a\left(a^{2}-b^{2}\right) f\left(a^{s n} x, a^{s n} y_{1}\right)\right)(t) \\
\geq \lim _{n \rightarrow \infty} a^{-5 s n} \psi\left(a^{s n} x, a^{s n} y_{1}, a^{s n} y_{2}\right)(t) \\
=1
\end{gathered}
$$

for all $x, y_{1}, y_{2} \in G$. This means that $T$ satisfies (1.9); that is, $T$ is quintic. 
According to the fixed point alternative, since $T$ is the unique fixed point of $J$ in the set $\Omega=\{g \in S: d(f, g)<\infty\}, T$ is the unique mapping such that

$$
v(f(x, y)-T(x, y))(u t) \geq \Phi(x, y)(t)
$$

for all $x, y \in G$ and $t>0$. Using the fixed point alternative, we obtain

$$
d(f, T) \leq \frac{1}{1-L} d(f, J f) \leq \frac{1}{1-k a^{-10 s}}
$$

which implies the inequality

$$
v(f(x, y)-T(x, y))\left(\frac{t}{1-k a^{-10 s}}\right) \geq \Phi(x, y)(t)
$$

for all $x, y \in G$ and $t>0$. Therefore, we have

$$
v(f(x, y)-T(x, y))(t) \geq \Phi(x, y)\left(\left(1-k a^{-10 s}\right) t\right)
$$

for all $x, y \in X G$ and $t>0$. This completes the proof.

Now, we investigate the stability problem for the system of the functional equations (1.10) form $r$-divisible groups into Šerstnev PB-space by using the fixed point theorem.

Theorem 2.2. Let $s \in\{-1,1\}$ be fixed. Let $G$ be an $r$-divisible group and $\left(Y, \nu, \Pi_{T}\right)$ a Šerstnev PB-space. Let $\Phi, \Psi, \Upsilon: G \times G \times G \times G \rightarrow D^{+}$be functions such that

$$
\begin{array}{r}
\Theta(x, y, z)(t):=\Pi_{T}\left\{\Upsilon\left(a^{(s+1) / 2} x, a^{(s+1) / 2} y, a^{(s+1) / 2} z, 0\right)\left(2 a^{3 s+3} t\right),\right. \\
\prod_{T}\left\{\Psi\left(a^{(s+1) / 2} x, a^{(s+1) / 2} y, 0, a^{(s-1) / 2} z\right)\left(2 a^{3 s+6} t\right),\right. \\
\left.\left.\Phi\left(a^{(s-1) / 2} x, 0, a^{(s-1) / 2} y, a^{(s-1) / 2} z\right)\left(2 a^{3 s+8} t\right)\right\}\right\}
\end{array}
$$

for all $x, y, z \in G$ and, for some $0<k<a^{6 s}$,

$$
\begin{aligned}
& \Phi\left(a^{s} x, a^{s} y, a^{s} z\right)(k t) \geq \Phi(x, y, z)(t) \\
& \lim _{n \rightarrow \infty} \Phi\left(a^{s n} x_{1}, a^{s n} x_{2}, a^{s n} y, a^{s n} z\right)\left(a^{-6 s n} t\right) \\
& \quad=\lim _{n \rightarrow \infty} \Psi\left(a^{s n} x, a^{s n} y_{1}, a^{s n} y_{2}, a^{s n} z\right)\left(a^{-6 s n} t\right) \\
& \quad=\lim _{n \rightarrow \infty} \Upsilon\left(a^{s n} x, a^{s n} y, a^{s n} z_{1}, a^{s n} z_{2}\right)\left(a^{-6 s n} t\right) \\
& \quad=1
\end{aligned}
$$


for all $x, y, x_{1}, x_{2}, y_{1}, y_{2}, z_{1}, z_{2} \in G$. If $f: G \times G \times G \rightarrow Y$ is a function such that $f(x, 0, z)=0$ for all $x, z \in G$ and

$$
\begin{aligned}
& v\left(f\left(a x_{1}+b x_{2}, y, z\right)+f\left(a x_{1}-b x_{2}, y, z\right)-2 a f\left(x_{1}, y, z\right)\right)(t) \geq \Phi\left(x_{1}, x_{2}, y, z\right)(t), \\
& v\left(f\left(x, a y_{1}+b y_{2}, z\right)+f\left(x, a y_{1}-b y_{2}, z\right)-2 a^{2} f\left(x, y_{1}, z\right)-2 b^{2} f\left(x, y_{2}, z\right)\right)(t) \\
& \quad \geq \Psi\left(x, y_{1}, y_{2}, z\right)(t) \\
& v\left(f\left(x, y, a z_{1}+b z_{2}\right)+f\left(x, y, a z_{1}-b z_{2}\right)\right. \\
& \left.\quad-a b^{2}\left(f\left(x, y, z_{1}+z_{2}\right)+f\left(x, y, z_{1}-z_{2}\right)\right)-2 a\left(a^{2}-b^{2}\right) f\left(x, y, z_{1}\right)\right)(t) \\
& \quad \geq \Upsilon\left(x, y, z_{1}, z_{2}\right)(t)
\end{aligned}
$$

for all $x, y, x_{1}, x_{2}, y_{1}, y_{2}, z_{1}, z_{2} \in G$, then there exists a unique quintic function $T: G \times G \times G \rightarrow Y$ satisfying (1.10) and

$$
v(f(x, y, z)-T(x, y, z))(t) \geq \Theta(x, y, z)\left(\left(1-k a^{-6 s}\right) t\right)
$$

for all $x, y, z \in G$.

Proof. Putting $x_{1}=2 x$ and $x_{2}=0$ and replacing $y, z$ by $2 y, 2 z$ in (2.26), we get

$$
v(f(2 a x, 2 y, 2 z)-a f(2 x, 2 y, 2 z))\left(\frac{1}{2} t\right) \geq \Phi(2 x, 0,2 y, 2 z)(t)
$$

for all $x, y, z \in G$. Putting $y_{1}=2 y$ and $y_{2}=0$ and replacing $x, z$ by $2 a x, 2 z$ in (2.27), we get

$$
v\left(f(2 a x, 2 a y, 2 z)-a^{2} f(2 a x, 2 y, 2 z)\right)\left(\frac{1}{2} t\right) \geq \Psi(2 a x, 2 y, 0,2 z)(t)
$$

for all $x, y, z \in G$. Putting $z_{1}=2 z$ and $z_{2}=0$ and replacing $x, y$ by $2 a x, 2 a y$ in (2.28), we get

$$
v\left(f(2 a x, 2 a y, 2 a z)-a^{3} f(2 a x, 2 a y, 2 z)\right)\left(\frac{1}{2} t\right) \geq \Upsilon(2 a x, 2 a y, 2 z, 0)(t),
$$

for all $x, y, z \in G$. Thus,

$$
\begin{aligned}
& v\left(f(2 a x, 2 a y, 2 a z)-a^{6} f(2 x, 2 y, 2 z)\right)(t) \\
& \quad \geq \Pi_{T}\left\{\Upsilon(2 a x, 2 a y, 2 z, 0)(2 t), \Pi_{T}\left\{\Psi(2 a x, 2 y, 0,2 z)\left(2 a^{3} t\right), \Phi(2 x, 0,2 y, 2 z)\left(2 a^{5} t\right)\right\}\right\}
\end{aligned}
$$


for all $x, y, z \in G$. Replacing $x, y$, and $z$ by $x / 2, y / 2$, and $z / 2$ in (2.33), we have

$$
\begin{aligned}
& v\left(f(a x, a y, a z)-a^{6} f(x, y, z)\right)(t) \\
& \quad \geq \Pi_{T}\left\{\Upsilon(a x, a y, z, 0)(2 t), \Pi_{T}\left\{\Psi(a x, y, 0, z)\left(2 a^{3} t\right), \Phi(x, 0, y, z)\left(2 a^{5} t\right)\right\}\right\}
\end{aligned}
$$

for all $x, y, z \in G$. It follows from (2.34) that

$$
\begin{gathered}
v\left(a^{-6} f(a x, a y, a z)-f(x, y, z)\right)(t) \\
\geq \Pi_{T}\left\{\Upsilon(a x, a y, z, 0)\left(2 a^{6} t\right), \Pi_{T}\left\{\Psi(a x, y, 0, z)\left(2 a^{9} t\right), \Phi(x, 0, y, z)\left(2 a^{11} t\right)\right\}\right\}, \\
v\left(a^{6} f\left(a^{-1} x, a^{-1} y, a^{-1} z\right)-f(x, y, z)\right)(t) \\
\geq \Pi_{T}\left\{\Upsilon\left(x, y, a^{-1} z, 0\right)(2 a t), \Pi_{T}\left\{\Psi\left(x, a^{-1} y, 0, a^{-1} z\right)\left(2 a^{3} t\right) \Phi\left(a^{-1} x, 0, a^{-1} y, a^{-1} z\right),\right.\right. \\
\left.\left.\left(2 a^{5} t\right)\right\}\right\}
\end{gathered}
$$

for all $x, y, z \in G$. Thus, we have

$$
v\left(a^{-6 s} f\left(a^{s} x, a^{s} y, a^{s} z\right)-f(x, y, z)\right)(t) \geq \Theta(x, y, z)(t)
$$

for all $x, y, z \in G$. Let $S$ be the set of all mappings $h: X \times X \times X \rightarrow Y$ with $h(x, 0, z)=0$ for all $x, z \in G$, and define a generalized metric on $S$ as follows:

$$
d(h, k)=\inf \left\{u \in \mathbb{R}^{+}: v(h(x, y, z)-k(x, y, z))(u t) \geq \Theta(x, y, z)(t), \forall x, y, z \in G, t>0\right\},
$$

where, as usual, $\inf \emptyset=+\infty$. The proof of the fact that $(S, d)$ is a complete generalized metric space can be shown in $[48,62]$.

Now, we consider the mapping $J: S \rightarrow S$ defined by

$$
J h(x, y, z):=a^{-6 s} h\left(a^{s} x, a^{s} y, a^{s} z\right)
$$

for all $h \in S$ and $x, y, z \in G$. Let $f, g \in S$ be such that $d(f, g)<\varepsilon$. Then we have

$$
\begin{aligned}
& v(J g(x, y, z)-J f(x, y, z))\left(k u a^{-6 s} t\right) \\
& \quad=v\left(a^{-6 s} g\left(a^{s} x, a^{s} y, a^{s} z\right)-a^{-6 s} f\left(a^{s} x, a^{s} y, a^{s} z\right)\right)\left(k u a^{-6 s} t\right) \\
& \quad=v\left(g\left(a^{s} x, a^{s} y, a^{s} z\right)-f\left(a^{s} x, a^{s} y, a^{s} z\right)\right)(k u t) \\
& \quad \geq \Theta\left(a^{s} x, a^{s} y, a^{s} z\right)(k t) \geq \Theta(x, y, z)(t),
\end{aligned}
$$


that is, if $d(f, g)<\varepsilon$, then we have $d(J f, J g)<k a^{-6 s} \varepsilon$. This means that

$$
d(J f, J g) \leq k a^{-6 s} d(f, g)
$$

for all $f, g \in S$; that is, $J$ is a strictly contractive self-mapping on $S$ with the Lipschitz constant $k a^{-6 s}$. It follows from (2.36) that

$$
v(J f(x, y, z)-f(x, y, z))(t) \geq \Theta(x, y, z)(t)
$$

for all $x, y, z \in G$ and all $t>0$, which implies that $d(J f, f) \leq 1$. From Theorem 1.3, it follows that there exists a unique mapping $T: G \times G \times G \rightarrow Y$ such that $T$ is a fixed point of $J$, that is, $T\left(a^{s} x, a^{s} y, a^{s} z\right)=a^{6 s} T(x, y, z)$ for all $x, y, z \in G$. Also, $d\left(J^{m} g, T\right) \rightarrow 0$ as $m \rightarrow \infty$, which implies the equality

$$
\lim _{m \rightarrow \infty} a^{-6 s m} f\left(a^{s m} x, a^{s m} y, a^{s m} z\right)=T(x)
$$

for all $x \in X$. It follows from (2.26), (2.27), and (2.28) that

$$
\begin{aligned}
& v\left(T\left(a x_{1}+b x_{2}, y, z\right)+T\left(a x_{1}-b x_{2}, y, z\right)-2 a T\left(x_{1}, y, z\right)\right)(t) \\
& =\lim _{n \rightarrow \infty} v\left(a^{-6 s n} f\left(a^{s n}\left(a x_{1}+b x_{2}\right), a^{s n} y, a^{s n} z\right)\right. \\
& \left.+a^{-6 s n} f\left(a^{s n}\left(a x_{1}-b x_{2}\right), a^{s n} y, a^{s n} z\right)-2 a a^{-6 s n} f\left(a^{s n} x_{1}, a^{s n} y, a^{s n} z\right)\right)(t) \\
& \geq \lim _{n \rightarrow \infty} \Phi\left(a^{s n} x_{1}, a^{s n} x_{2}, a^{s n} y, a^{s n} z\right)\left(a^{-6 s n} t\right) \\
& =1 \text {, } \\
& v\left(T\left(x, a y_{1}+b y_{2}, z\right)+T\left(x, a y_{1}-b y_{2}, z\right)-2 a^{2} T\left(x, y_{1}, z\right)-2 b^{2} T\left(x, y_{2}, z\right)\right)(t) \\
& =\lim _{n \rightarrow \infty} v\left(a^{-6 s n} f\left(a^{s n} x, a^{s n}\left(a y_{1}+b y_{2}\right), a^{s n} z\right)+f\left(a^{s n} x, a^{s n} a y_{1}-a^{s n} b y_{2}, a^{s n} z\right)\right. \\
& \left.-2 a^{2} a^{-6 s n} f\left(a^{s n} x, a^{s n} y_{1}, a^{s n} z\right)+2 b^{2} a^{-6 s n} f\left(a^{s n} x, a^{s n} y_{2}, a^{s n} z\right)\right)(t) \\
& \geq \lim _{n \rightarrow \infty} \Psi\left(a^{s n} x, a^{s n} y_{1}, a^{s n} y_{2}, a^{s n} z\right)\left(a^{-6 s n} t\right) \\
& =1 \text {, } \\
& v\left(T\left(x, y, a z_{1}+b z_{2}\right)+T\left(x, y, a z_{1}-b z_{2}\right)-a b^{2}\left(T\left(x, y, z_{1}+z_{2}\right)\right.\right. \\
& \left.\left.-T\left(x, y, z_{1}-z_{2}\right)\right)-2 a\left(a^{2}-b^{2}\right) T\left(x, y, z_{1}\right)\right)(t) \\
& =\lim _{n \rightarrow \infty} v\left(a^{-6 s n} f\left(a^{s n} x, a^{s n} y, a^{s n}\left(a z_{1}+b z_{2}\right)\right)\right.
\end{aligned}
$$




$$
\begin{aligned}
& \quad+a^{-6 s n} f\left(a^{s n} x, a^{s n} y, a^{s n}\left(a z_{1}-b z_{2}\right)\right)-a b^{2} a^{-6 s n}\left(f\left(a^{s n} x, a^{s n} y, a^{s n}\left(z_{1}+z_{2}\right)\right)\right. \\
& \left.\left.\quad+f\left(a^{s n} x, a^{s n} y, a^{s n}\left(z_{1}-z_{2}\right)\right)\right)-2 a a^{-6 s n}\left(a^{2}-b^{2}\right) f\left(a^{s n} x, a^{s n} y, a^{s n} z_{1}\right)\right)(t) \\
& \geq \lim _{n \rightarrow \infty} \Upsilon\left(a^{s n} x, a^{s n} y, a^{s n} z_{1}, a^{s n} z_{2}\right)\left(a^{-6 s n} t\right) \\
& =1
\end{aligned}
$$

for all $x, y, x_{1}, x_{2}, y_{1}, y_{2}, z_{1}, z_{2} \in G$. This means that $T$ satisfies (1.10); that is, $T$ is sextic. According to the fixed point alternative, since $T$ is the unique fixed point of $J$ in the set $\Omega=\{g \in S: d(f, g)<\infty\}, T$ is the unique mapping such that

$$
v(f(x, y, z)-T(x, y, z))(u t) \geq \Theta(x, y, z)(t)
$$

for all $x, y, z \in G$ and $t>0$. Using the fixed point alternative, we obtain

$$
d(f, T) \leq \frac{1}{1-L} d(f, J f) \leq \frac{1}{1-k a^{-6 s}},
$$

which implies the inequality

$$
v(f(x, y, z)-T(x, y, z))\left(\frac{t}{1-k a^{-6 s}}\right) \geq \Theta(x, y, z)(t)
$$

for all $x, y, z \in G$ and $t>0$. So

$$
v(f(x, y, z)-T(x, y, z))(t) \geq \Theta(x, y, z)\left(\left(1-k a^{-6 s}\right) t\right)
$$

for all $x, y, z \in G$ and $t>0$. This completes the proof.

\section{Acknowledgment}

The second author was supported by the Korea Research Foundation Grant funded by the Korean Government (KRF-2008-313-C00050).

\section{References}

[1] S. M. Ulam, Problems in Modern Mathematics, chapter 6, John Wiley \& Sons, New York, NY, USA, 1964.

[2] D. H. Hyers, "On the stability of the linear functional equation," Proceedings of the National Academy of Sciences of the United States of America, vol. 27, pp. 222-224, 1941.

[3] T. Aoki, "On the stability of the linear transformation in Banach spaces," Journal of the Mathematical Society of Japan, vol. 2, pp. 64-66, 1950.

[4] Th. M. Rassias, "On the stability of the linear mapping in Banach spaces," Proceedings of the American Mathematical Society, vol. 72, no. 2, pp. 297-300, 1978. 
[5] Th. M. Rassias, "New characterizations of inner product spaces," Bulletin des Sciences Mathématiques, vol. 108, no. 1, pp. 95-99, 1984.

[6] P. Găvruţa, "A generalization of the Hyers-Ulam-Rassias stability of approximately additive mappings," Journal of Mathematical Analysis and Applications, vol. 184, no. 3, pp. 431-436, 1994.

[7] P. W. Cholewa, "Remarks on the stability of functional equations," Aequationes Mathematicae, vol. 27, no. 1-2, pp. 76-86, 1984.

[8] St. Czerwik, "On the stability of the quadratic mapping in normed spaces," Abhandlungen aus dem Mathematischen Seminar der Universität Hamburg, vol. 62, pp. 59-64, 1992.

[9] S. Czerwik, Functional Equations and Inequalities in Several Variables, World Scientific, London, UK, 2002.

[10] M. Eshaghi Gordji and H. Khodaei, "Solution and stability of generalized mixed type cubic, quadratic and additive functional equation in quasi-Banach spaces," Nonlinear Analysis: Theory, Methods $\mathcal{E}$ Applications, vol. 71, no. 11, pp. 5629-5643, 2009.

[11] H. Khodaei and T.M. Rassias, "Approximately generalized additive functions in several variables," International Journal of Nonlinear Analysis and Applications, vol. 1, pp. 22-41, 2010.

[12] Z. Gajda, "On stability of additive mappings," International Journal of Mathematics and Mathematical Sciences, vol. 14, no. 3, pp. 431-434, 1991.

[13] P. Gãvruta and L. Gãvruta, “A new method for the generalized Hyers-Ulam-Rassias stability," International Journal of Nonlinear Analysis and Applications, vol. 1, no. 2, pp. 11-18, 2010.

[14] D. H. Hyers, G. Isac, and T. M. Rassias, Stability of Functional Equations in Several Variables, Birkhäuser, Basel, Switzerland, 1998.

[15] D. H. Hyers and T. M. Rassias, “Approximate homomorphisms," Aequationes Mathematicae, vol. 44, no. 2-3, pp. 125-153, 1992.

[16] S.-M. Jung, Hyers-Ulam-Rassias Stability of Functional Equations in Mathematical Analysis, Hadronic Press, Palm Harbor, Fla, USA, 2001.

[17] S.-M. Jung, "Hyers-Ulam-Rassias stability of Jensen's equation and its application," Proceedings of the American Mathematical Society, vol. 126, no. 11, pp. 3137-3143, 1998.

[18] G. Isac and T. M. Rassias, "On the Hyers-Ulam stability of $\psi$-additive mappings," Journal of Approximation Theory, vol. 72, no. 2, pp. 131-137, 1993.

[19] G. Isac and T. M. Rassias, "Stability of $\psi$-additive mappings: applications to nonlinear analysis," International Journal of Mathematics and Mathematical Sciences, vol. 19, no. 2, pp. 219-228, 1996.

[20] S.-M. Jung, "Stability of the quadratic equation of Pexider type," Abhandlungen aus dem Mathematischen Seminar der Universität Hamburg, vol. 70, pp. 175-190, 2000.

[21] Th. M. Rassias, "On the stability of functional equations in Banach spaces," Journal of Mathematical Analysis and Applications, vol. 251, no. 1, pp. 264-284, 2000.

[22] C.-G. Park, "On an approximate automorphism on a $C^{*}$-algebra," Proceedings of the American Mathematical Society, vol. 132, no. 6, pp. 1739-1745, 2004

[23] C. Park and M. E. Gordji, "Comment on "Approximate ternary Jordan derivations on Banach ternary algebras" [Bavand Savadkouhi J. Math. Phys. 50, 042303 (2009)]," Journal of Mathematical Physics, vol. 51, no. 4, Article ID 044102, 7 pages, 2010.

[24] C. Park and A. Najati, "Generalized additive functional inequalities in Banach algebras," International Journal of Nonlinear Analysis and Applications, vol. 1, no. 2, pp. 54-62, 2010.

[25] C. Park and T. M. Rassias, "Isomorphisms in unital $C^{*}$-algebras," International Journal of Nonlinear Analysis and Applications, vol. 1, pp. 1-10, 2010.

[26] C. Park and J. M. Rassias, "Stability of the Jensen-type functional equation in $C^{*}$-algebras: a fixed point approach," Abstract and Applied Analysis, vol. 2009, Article ID 360432, 17 pages, 2009.

[27] V. Radu, "The fixed point alternative and the stability of functional equations," Fixed Point Theory, vol. 4, no. 1, pp. 91-96, 2003.

[28] Th. M. Rassias, "On the stability of the linear mapping in Banach spaces," Proceedings of the American Mathematical Society, vol. 72, no. 2, pp. 297-300, 1978.

[29] I. A. Rus, Principles and Applications of Fixed Point Theory, Editura Dacia, Cluj-Napoca, Romania, 1979.

[30] Th. M. Rassias and P. Šemrl, "On the behavior of mappings which do not satisfy Hyers-Ulam stability," Proceedings of the American Mathematical Society, vol. 114, no. 4, pp. 989-993, 1992.

[31] J. Aczél and J. Dhombres, Functional Equations in Several Variables, vol. 31, Cambridge University Press, Cambridge, UK, 1989.

[32] P. Kannappan, "Quadratic functional equation and inner product spaces," Results in Mathematics, vol. 27, no. 3-4, pp. 368-372, 1995. 
[33] F. Skof, "Propriet locali e approssimazione di operatori," Rendiconti del Seminario Matematico e Fisico di Milano, vol. 53, pp. 113-129, 1983.

[34] M. Eshaghi Gordji and H. Khodaei, "On the generalized Hyers-Ulam-Rassias stability of quadratic functional equations," Abstract and Applied Analysis, vol. 2009, Article ID 923476, 11 pages, 2009.

[35] K.-W. Jun and H.-M. Kim, "The generalized Hyers-Ulam-Rassias stability of a cubic functional equation," Journal of Mathematical Analysis and Applications, vol. 274, no. 2, pp. 267-278, 2002.

[36] K.-W. Jun, H.-M. Kim, and I.-S. Chang, "On the Hyers-Ulam stability of an Euler-Lagrange type cubic functional equation," Journal of Computational Analysis and Applications, vol. 7, no. 1, pp. 21-33, 2005.

[37] A. Najati, "Hyers-Ulam-Rassias stability of a cubic functional equation," Bulletin of the Korean Mathematical Society, vol. 44, no. 4, pp. 825-840, 2007.

[38] S. H. Lee, S. M. Im, and I. S. Hwang, "Quartic functional equations," Journal of Mathematical Analysis and Applications, vol. 307, no. 2, pp. 387-394, 2005.

[39] J. K. Chung and P. K. Sahoo, "On the general solution of a quartic functional equation," Bulletin of the Korean Mathematical Society, vol. 40, no. 4, pp. 565-576, 2003.

[40] A. Ebadian, A. Najati, and M. Eshaghi Gordji, "On approximate additive-quartic and quadratic-cubic functional equations in two variables on abelian groups," Results in Mathematics, vol. 58, no. 1-2, pp. 39-53, 2010.

[41] M. Eshaghi Gordji, "Stability of a functional equation deriving from quartic and additive functions," Bulletin of the Korean Mathematical Society, vol. 47, no. 3, pp. 491-502, 2010.

[42] M. Eshaghi Gordji, M. B. Ghaemi, S. Kaboli Gharetapeh, S. Shams, and A. Ebadian, “On the stability of $J^{*}$-derivations," Journal of Geometry and Physics, vol. 60, no. 3, pp. 454-459, 2010.

[43] M. Eshaghi-Gordji, S. K. Gharetapeh, C. Park, and S. Zolfaghari, "Stability of an additive-cubic-quartic functional equation," Advances in Difference Equations, vol. 2009, Article ID 395693, 20 pages, 2009.

[44] M. Eshaghi Gordji, S. Kaboli Gharetapeh, J. M. Rassias, and S. Zolfaghari, "Solution and stability of a mixed type additive, quadratic, and cubic functional equation," Advances in Difference Equations, vol. 2009, Article ID 826130, 17 pages, 2009.

[45] M. B. Ghaemi, M. Eshaghi Gordji, and H. Majani, “Approximately quintic and sextic mappings on the probabilistic normed spaces," preprint.

[46] B. Margolis and J. B. Diaz, "A fixed point theorem of the alternative for contractions on the generalized complete metric space," Bulletin of the American Mathematical Society, vol. 126, pp. 305-309, 1968.

[47] E. Zeidler, Nonlinear Functional Analysis and Its Applications: Part 1: Fixed-Point Theorems , Springer, New York, NY, USA, 1986.

[48] L. Cădariu and V. Radu, "On the stability of the Cauchy functional equation: a fixed point approach," in Iteration Theory, vol. 346 of Grazer Mathematische Berichte, pp. 43-52, Karl-Franzens-Universitaet Graz, Graz, Austria, 2004.

[49] L. Cădariu and V. Radu, "Fixed points and the stability of Jensen's functional equation," Journal of Inequalities in Pure and Applied Mathematics, vol. 4, no. 1, article 4, 7 pages, 2003.

[50] A. Ebadian, N. Ghobadipour, and M. Eshaghi Gordji, "A fixed point method for perturbation of bimultipliers and Jordan bimultipliers in $C^{*}$-ternary algebras," Journal of Mathematical Physics, vol. 51, Article ID 103508, 10 pages, 2010.

[51] M. Eshaghi Gordji and H. Khodaei, "The fixed point method for fuzzy approximation of a functional equation associated with inner product spaces," Discrete Dynamics in Nature and Society, vol. 2010, Article ID 140767, 15 pages, 2010.

[52] M. Eshaghi Gordji, H. Khodaei, and R. Khodabakhsh, "General quartic-cubic-quadratic functional equation in non-Archimedean normed spaces," Scientific Bulletin-University Politehnica of Bucharest, vol. 72, no. 3, pp. 69-84, 2010.

[53] M. Eshaghi Gordji and A. Najati, "Approximately J*-homomorphisms: a fixed point approach," Journal of Geometry and Physics, vol. 60, no. 5, pp. 809-814, 2010.

[54] A. N. Šerstnev, "On the motion of a random normed space," Doklady Akademii Nauk SSSR, vol. 149, pp. 280-283, 1963, English Translation in Soviet Mathematics Doklady, vol. 4, pp. 388-390, 1963.

[55] C. Alsina, B. Schweizer, and A. Sklar, "On the definition of a probabilistic normed space," Aequationes Mathematicae, vol. 46, no. 1-2, pp. 91-98, 1993.

[56] B. Schweizer and A. Sklar, Probabilistic Metric Spaces, Elsevier, New York, NY, USA, 1983.

[57] S.-S. Chang, Y. J. Cho, and S. M. Kang, Nonlinear Operator Theory in Probabilistic Metric Spaces, Nova Science, Huntington, NY, USA, 2001.

[58] M. Eshaghi Gordji and M. B. Savadkouhi, "Stability of mixed type cubic and quartic functional equations in random normed spaces," Journal of Inequalities and Applications, vol. 2009, Article ID 527462, 9 pages, 2009. 
[59] M. Eshaghi Gordji, M. B. Ghaemi, and H. Majani, "Generalized Hyers-Ulam-Rassias theorem in Menger probabilistic normed spaces," Discrete Dynamics in Nature and Society, vol. 2010, Article ID 162371, 11 pages, 2010.

[60] M. Eshaghi Gordji, M. B. Ghaemi, H. Majani, and C. Park, "Generalized Ulam-Hyers stability of Jensen functional equation in Šerstnev PN spaces," Journal of Inequalities and Applications, vol. 2010, Article ID 868193, 14 pages, 2010.

[61] M. Eshaghi Gordji, M. B. Savadkouhi, and C. Park, "Quadratic-quartic functional equations in RNspaces," Journal of Inequalities and Applications, vol. 2009, Article ID 868423, 14 pages, 2009.

[62] O. Hadžić, E. Pap, and V. Radu, "Generalized contraction mapping principles in probabilistic metric spaces," Acta Mathematica Hungarica, vol. 101, no. 1-2, pp. 131-148, 2003. 


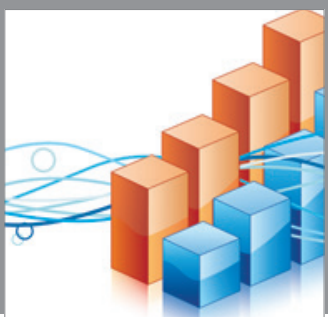

Advances in

Operations Research

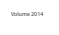

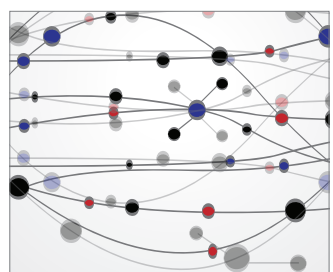

\section{The Scientific} World Journal
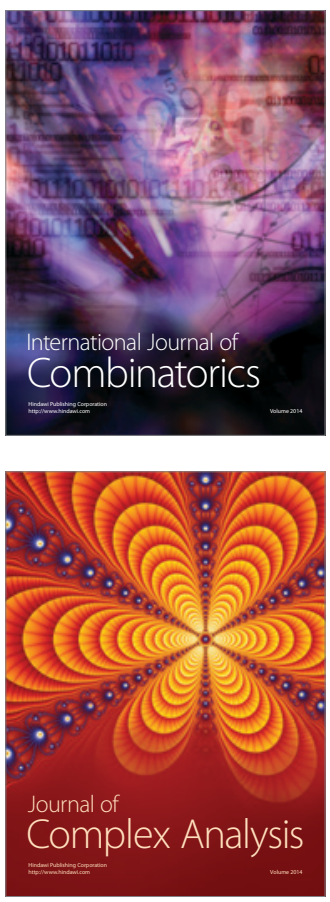

International Journal of

Mathematics and

Mathematical

Sciences
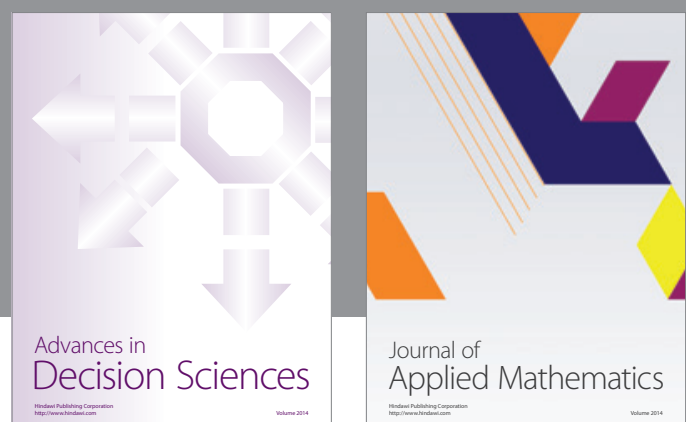

Journal of

Applied Mathematics
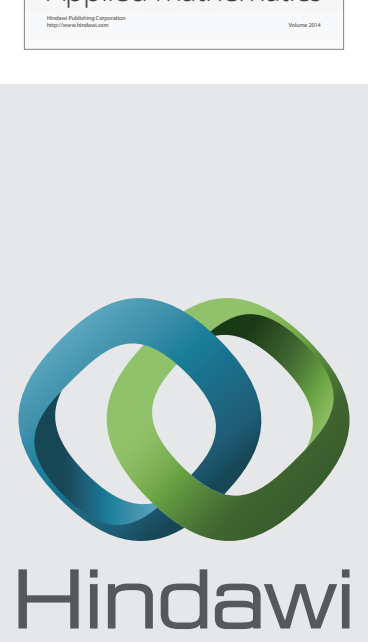

Submit your manuscripts at http://www.hindawi.com
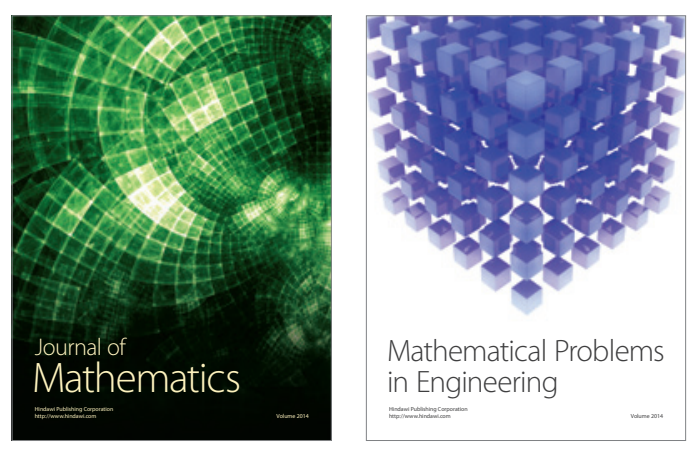

Mathematical Problems in Engineering
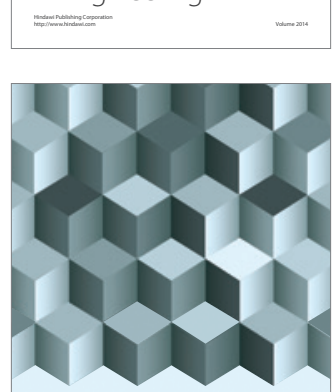

Journal of

Function Spaces
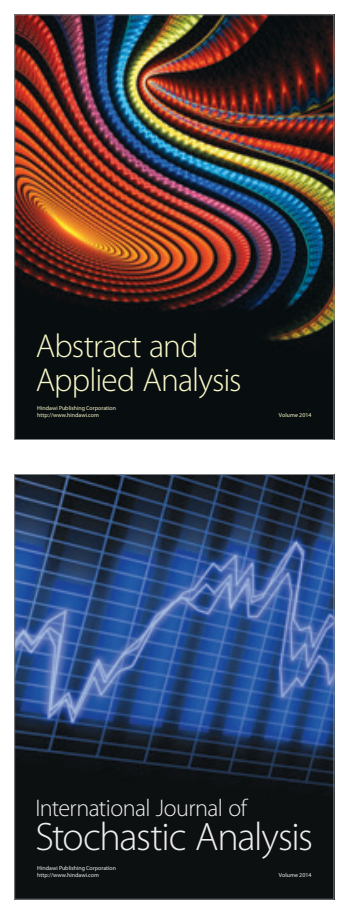

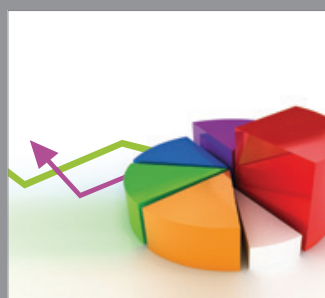

ournal of

Probability and Statistics

Promensencen
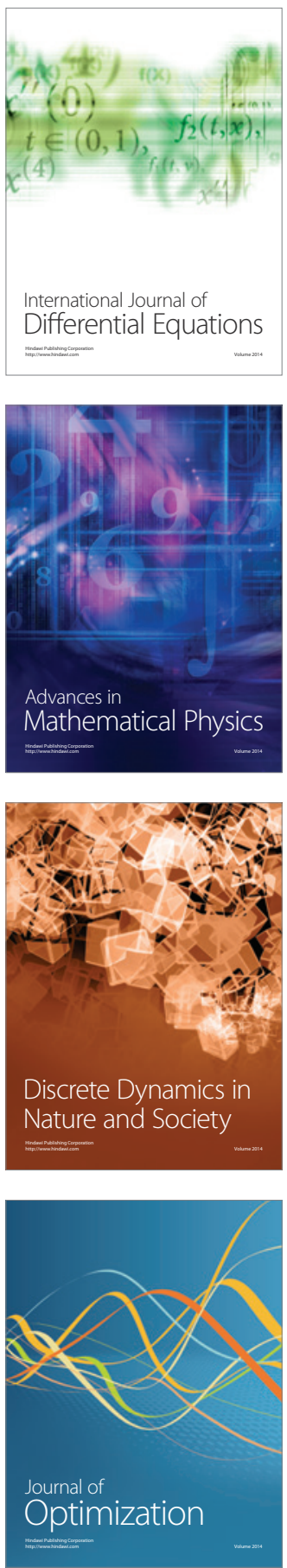